\title{
DESCOLORAÇÃO REDUTIVA DE CORANTES AZO E O EFEITO DE MEDIADORES REDOX NA PRESENÇA DO ACEPTOR DE ELÉTRONS SULFATO
}

\author{
Mayara Carantino Costa, André Bezerra dos Santos* e Francisco Suetônio B. Mota \\ Departamento de Engenharia Hidráulica e Ambiental, Universidade Federal do Ceará, Campus do Pici, 60451-970 Fortaleza-CE, Brasil \\ Glaydson Leandro Farias Mendonça e Ronaldo Ferreira do Nascimento \\ Departamento de Química Analítica e Físico-Química, Universidade Federal do Ceará, Campus do Pici, 60451-970 Fortaleza - CE, Brasil
}

Recebido em 20/10/09; aceito em 5/4/10; publicado na web em 9/8/10

\begin{abstract}
REDUCTIVE DECOLOURISATION OF AZO DYES AND THE EFFECT OF REDOX MEDIATORS IN THE PRESENCE OF THE ELECTRON ACCEPTOR SULFATE. We investigated the impact of sulphate and the redox mediator Anthraquinone-2,6disulfonate (AQDS) on the decolorization of the azo dyes Congo Red (CR) and Reactive Black 5 (RB5). In anaerobic reactors free of extra sulphate dosage, the color removal efficiency decreased drastically when the external electron donor ethanol was removed. In presence of an extra dosage of sulphate, CR decolourisations were 47.8\% (free of AQDS) and 96.5\% (supplemented with AQDS). The decolourisations achieved in both reactors with RB5 were lower than the ones found with CR. Finally, the biogenic sulphide contribution on azo dye reduction was negligiable.
\end{abstract}

Keywords: color removal; redox mediators; sulphate.

\section{INTRODUÇÃO}

O processo de tingimento de tecidos é uma atividade que começou há milhares de anos e atualmente existe uma variedade e enorme disponibilidade comercial de corantes para as indústrias têxteis, com o objetivo de atender à demanda por criatividade e ao desejo de inovação. ${ }^{1}$ Os corantes são classificados de acordo com sua estrutura molecular, sendo a classe mais importante a dos corantes azo. Estes são caracterizados pela presença de um ou mais grupos azo $(-\mathrm{N}=\mathrm{N}-)$, além de formarem ligações entre dois ou mais anéis aromáticos. ${ }^{2}$

Há uma preocupação com os efluentes gerados pelas indústrias têxteis, pois o processo de tintura envolve uma etapa final de lavagem em banhos correntes para retirada do excesso de corante original ou que não foi fixado à fibra nas etapas precedentes. Adicionalmente, corantes são utilizados nos processos de estamparia, presentes em algumas indústrias têxteis. Desta forma, efluentes têxteis lançados no meio ambiente causam problemas ambientais e de saúde pública, pois a presença de cor nas águas superficiais é esteticamente desagradável, pode afetar a fotossíntese das algas e comprometer a vida aquática. ${ }^{1,3}$ Por serem tóxicos e carcinogênicos, podem trazer sérios problemas ao homem. Adicionalmente, os produtos da degradação de corantes azo, as aminas aromáticas, são compostos químicos perigosos, carcinogênicos e tóxicos à vida aquática. ${ }^{4}$

Muitas técnicas, tanto físicas, químicas e biológicas ou uma combinação destes processos, têm sido utilizadas para descoloração, sendo que os processos biológicos são mais frequentes, por serem mais atrativos economicamente. ${ }^{5}$

A remoção de cor de corantes azo é resultado da quebra da ligação azo, sendo o corante um aceptor final de elétrons. Como o oxigênio é um melhor aceptor de elétrons do que os corantes, processos biológicos aeróbios de remoção de cor por bactérias tendem a ser de baixa eficiência de remoção de cor. Entretanto, sob condições anaeróbias, o potencial redox alcançado é mais propício para o processo de redução dos corantes, o que faz com que os micro-organismos anaeróbios sejam mais efetivos em transferir os elétrons gerados nos processos oxidativos, e sejam alcançadas maiores taxas de descoloração. ${ }^{3,6-8}$

*e-mail: andre23@ufc.br
Ressalta-se a importância de um pós-tratamento do efluente anaeróbio, pois as aminas aromáticas produzidas são normalmente resistentes à biodegradação em ambientes anaeróbios. Entretanto, há relatos de sua mineralização sob condições aeróbias numa combinação de processos de biodegradação, auto-oxidação e adsorção. .,9,10 $^{4}$ Outros processos não biológicos, como o Processo de Oxidação Avançado (POA), ozônio e adsorção, têm sido aplicados como pós-tratamento de efluentes anaeróbios, com resultados bastante promissores. Em relação ao POA, as constantes de primeira ordem $\left(\mathrm{k}_{1}\right)$ obtidas, normalmente em $\mathrm{min}^{-1}$, podem vir a compensar os maiores custos deste tratamento para o efluente bruto quando se tem compostos muito recalcitrantes. ${ }^{11-14}$

O processo anaeróbio de redução de corantes normalmente requer longos tempos de reação e, portanto, reatores anaeróbios de maior volume, o que representa maiores custos e demanda de área. No entanto, isto poderia ser atenuado utilizando-se compostos quinônicos, que podem funcionar como mediadores redox durante a transferência de elétrons em reações puramente químicas ou bioquímicas. ${ }^{10,15}$ Inicialmente, os mediadores redox são enzimaticamente reduzidos pelos micro-organismos anaeróbios presentes, então há a transferência dos elétrons para os corantes em uma reação puramente química e a regeneração dos mediadores redox, funcionando estes como um catalisador. ${ }^{6,16}$ Os custos oriundos da dosagem de mediadores redox, mesmo estes sendo normalmente utilizados na concentração de $\mu \mathrm{g} / \mathrm{L}$, poderiam ser diminuídos enormemente com a imobilização destes nos reatores biológicos, por exemplo, utilizando-se as quinonas presentes no carvão ativado, ou mesmo no uso de nanoestruturas ou esferas de alginato para imobilização destes compostos. ${ }^{11,17-19}$

A presença e disponibilidade de um cossubstrato, que funcionará como doador de elétrons na reação de descoloração, são importantes condições para boa capacidade de remoção de cor em bioreatores operados sob condições anaeróbias. ${ }^{10}$ Adicionalmente, as condições operacionais como $\mathrm{pH}$, temperatura e concentração do corante também afetam as taxas de descoloração. ${ }^{20}$

As reações bioquímicas, como as envolvidas nos processos de remoção de cor, tanto na presença quanto na ausência de mediador redox, podem ser afetadas devido à presença de sulfato ou nitrato, que são constituintes comuns em efluentes têxteis. Estes compostos podem 
funcionar como aceptores alternativos de elétrons, competindo com o corante por elétrons, inibindo assim o processo de descoloração. ${ }^{9,21,22}$

Além disso, o sulfato poderá ser reduzido biologicamente a sulfeto biogênico, que pode funcionar como doador de elétrons, estimulando a remoção de cor. ${ }^{9,10,23}$ Portanto, a literatura ainda é bastante contraditória quanto ao efeito desses aceptores de elétrons, principalmente na presença de mediadores redox.

O presente trabalho teve como objetivo avaliar o efeito da presença de sulfato na descoloração dos corantes azo Congo Red e Reactive Black 5 por lodo anaeróbio, tanto na presença como na ausência do Antraquinona-2,6-disulfonado (AQDS), em experimentos em fluxo contínuo e em batelada.

\section{PARTE EXPERIMENTAL}

\section{Corantes e compostos químicos}

Os corantes azo selecionados foram o Congo Red (CR) (qualidade analítica, Vetec) e o Reactive Black 5 (RB5) (pureza de 55\%, SigmaAldrich), cujas estruturas moleculares são mostradas nas Figuras $1 \mathrm{e}$ 2. Ambos os corantes são diazos, com pesos moleculares de 696,98 $\mathrm{g} / \mathrm{mol}$ (CR) e de 991,82 g/mol (RB5). O composto AQDS (pureza de 98\%, Aldrich Chemical Company) foi selecionado como mediador redox e o composto etanol como cossubstrato ou doador de elétrons.

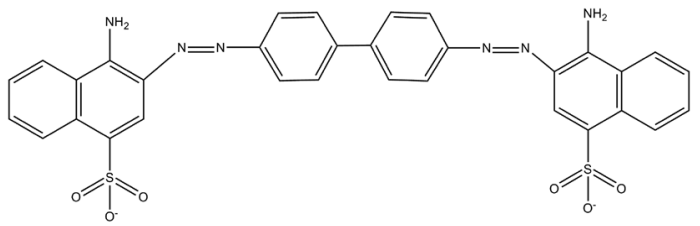

Figura 1. Estrutura molecular do corante Congo Red

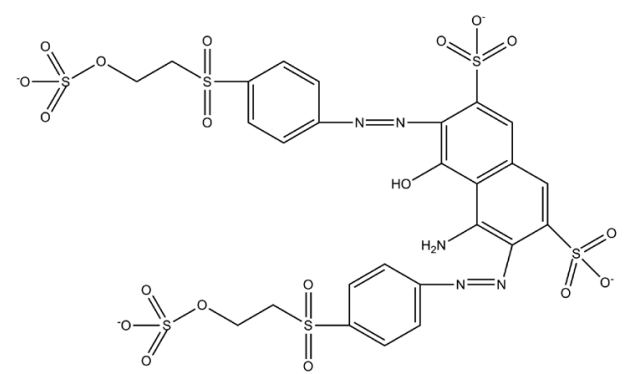

Figura 2. Estrutura molecular do corante Reactive Black 5

\section{Fonte de lodo anaeróbio e meio basal}

O lodo foi coletado em um reator tipo UASB (Upflow Anaerobic Sludge Blanket) de uma indústria de cerveja em Fortaleza, Ceará, Brasil. O meio basal utilizado nos experimentos em fluxo contínuo e em batelada consistia de (mg/L): $\mathrm{NH}_{4} \mathrm{Cl}(280), \mathrm{K}_{2} \mathrm{HPO}_{4}(250), \mathrm{MgSO}_{4} \cdot 7 \mathrm{H}_{2} \mathrm{O}$ (100) e $\mathrm{CaCl}_{2} \cdot 2 \mathrm{H}_{2} \mathrm{O}(10)$ e $1 \mathrm{~mL} / \mathrm{L}$ de elementos traços que continha (mg/L): $\mathrm{H}_{3} \mathrm{BO}_{3}(50), \mathrm{FeCl}_{2} \cdot 4 \mathrm{H}_{2} \mathrm{O}(2000), \mathrm{ZnCl}_{2}(50), \mathrm{MnCl}_{2} \cdot 4 \mathrm{H}_{2} \mathrm{O}$ (500), $\mathrm{CuCl}_{2} \cdot 2 \mathrm{H}_{2} \mathrm{O}(38),\left(\mathrm{NH}_{4}\right)_{6} \mathrm{Mo}_{7} \mathrm{O}_{24} \cdot 4 \mathrm{H}_{2} \mathrm{O}(50), \mathrm{AlCl}_{3} \cdot 6 \mathrm{H}_{2} \mathrm{O}(90)$, $\mathrm{CoCl}_{2} \cdot 6 \mathrm{H}_{2} \mathrm{O}(2000), \mathrm{NiCl}_{2} \cdot 6 \mathrm{H}_{2} \mathrm{O}(92), \mathrm{Na}_{2} \mathrm{SeO}_{3} \cdot 5 \mathrm{H}_{2} \mathrm{O}(162)$, EDTA (1000) e $1 \mu \mathrm{L} / \mathrm{L}$ de $\mathrm{HCl} 36 \%$. O meio basal foi tamponado para manter o pH próximo de 7,1 com bicarbonato de sódio (2,5g/L).

Efeito de diferentes concentrações de sulfato na redução de corantes azo por lodo anaeróbio

Utilizou-se em todos os experimentos em batelada uma concen- tração inicial de lodo anaeróbio de 1,5 gSSV (Sólidos Suspensos Voláteis)/L. O consórcio anaeróbio foi transferido às garrafas em série de $117 \mathrm{~mL}$, sendo $50 \mathrm{~mL}$ preenchido com meio basal.

Após as garrafas serem tampadas com borrachas do tipo butil e lacradas com prendedores de alumínio, o meio gasoso foi trocado injetando-se gás $\mathrm{N}_{2} / \mathrm{CO}_{2}$ (70\%:30\%) e expurgando o meio por aproximadamente 1 min para o estabelecimento de condições anaeróbias.

Em seguida, cossubstrato (quando testado), corante, mediador redox (quando testado) e fonte extra de sulfato (quando testada) foram adicionados às garrafas, que foram colocadas numa mesa agitadora a $150 \mathrm{rpm}$. O experimento foi conduzido em duplicata. A mesa agitadora permaneceu numa sala com temperatura ambiente de $28 \pm 2{ }^{\circ} \mathrm{C}$.

Os corantes foram testados na concentração de $0,3 \mathrm{mM}$ e o mediador redox AQDS foi testado na concentração de $50 \mu \mathrm{M}$. O cossubstrato etanol foi adicionado na concentração de 1,5 gDQO (Demanda Química de Oxigênio)/L. O aceptor de elétrons sulfato foi testado nas concentrações de 100, 250, 500 e 1000 mg/L.

Efeito da presença de sulfato na descoloração redutiva de corantes azo em reatores anaeróbios suplementados e livres de AQDS

Foram utilizados quatro reatores anaeróbios de vidro do tipo UASB, com volume útil de $0,53 \mathrm{~L}$, operados com um tempo de detenção hidráulica (TDH) de $8 \mathrm{~h}$ e mantidos em temperatura ambiente de $28 \pm 2$ ${ }^{\circ} \mathrm{C}$. Os reatores foram preenchidos com lodo anaeróbio e acrescentou-se água destilada, até completar $2 / 3$ da altura de cada reator.

Os reatores controle, nos quais não se adicionava fonte extra de sulfato, foram denominados R1 (livre de AQDS) e R2 (suplementado com AQDS). Os reatores de redução de sulfato, acrescidos de 250 $\mathrm{mg} / \mathrm{L}$ de sulfato de sódio no meio basal, foram denominados de R3 (suplementado com sulfato, mas livre de AQDS) e R4 (suplementado com sulfato e AQDS).

O corante azo CR foi testado nas concentrações de 0,6 e 1,2 mM. O corante RB5 foi adicionado na concentração de $0,3 \mathrm{mM}$.

Inicialmente a carga orgânica volumétrica $(\mathrm{COV})$ do doador de elétrons etanol foi de $2,5 \mathrm{kgDQO} / \mathrm{m}^{3} \mathrm{dia}$, a qual foi variada nas outras fases do experimento. Foi feito também um teste sem a adição de etanol, para analisar o efeito da ausência de um doador de elétrons nas taxas de descoloração em reatores anaeróbios, além de avaliar a capacidade do consórcio microbiano de utilizar o corante como fonte de carbono e energia.

\section{Análises e cálculos}

A remoção de cor foi determinada fotometricamente no comprimento de onda de maior absorbância de cada corante (Thermo - Nicolet Evolution 100). As amostras eram diluídas com fator de diluição 5, usando-se uma solução tampão de fosfato em microtubos de Eppendorff. Para evitar a interferência devido à turbidez provocada por material suspenso, as amostras foram centrifugadas a $13.000 \mathrm{rpm}$ por $2 \mathrm{~min}$.

Os parâmetros operacionais dos reatores como $\mathrm{pH}$, alcalinidade, ácidos graxos voláteis (AGV) e DQO foram analisados duas vezes por semana, de acordo com o Standard Methods, ${ }^{24}$ tanto em amostras dos afluentes como dos efluentes dos reatores.

Foram feitas análises de sulfato por cromatografia de íons, para verificar a ocorrência de redução de sulfato nos reatores anaeróbios.

Assumindo-se uma cinética de pseudoprimeira ordem em relação à concentração do corante, calculou-se a constante cinética $\mathrm{k}_{1}$, seguindo a Equação 1:

$$
A_{t}=A_{0} \cdot e^{-k}{ }_{1}
$$

onde: $\mathrm{A}_{\mathrm{t}}=$ absorbância no tempo $\mathrm{t}, \mathrm{A}_{0}=$ absorbância no tempo $\mathrm{t}=0$, 
$\mathrm{k}_{1}=$ constante de pseudoprimeira ordem $\left(\right.$ dia $\left.^{-1}\right)$ e $\mathrm{t}=$ tempo acumulado do experimento (dias). O tempo era plotado contra $\ln \left(\mathrm{A}_{\mathrm{t}} / \mathrm{A}_{0}\right)$ e o valor de $\mathrm{k}_{1}$ era estimado pelo coeficiente angular da regressão linear.

\section{RESULTADOS E DISCUSSÃO}

\section{Impacto de diferentes concentrações de sulfato na descoloração redutiva de corantes azo}

Foram realizados testes em batelada para se avaliar o efeito do gradiente de concentração do sulfato nas taxas de remoção de cor do corante azo CR na presença e na ausência de mediador redox, cujos resultados podem ser vistos nas Tabelas 1 e 2 .

Tabela 1. Taxas de descoloração do corante azo CR na presença de diferentes concentrações de sulfato com a adição do cossubstrato etanol (1,5 gDQO/L)

\begin{tabular}{ccccc}
\hline $\begin{array}{c}\text { Concentração de } \\
\text { sulfato }(\mathrm{mg} / \mathrm{L})\end{array}$ & $\begin{array}{c}\text { Corante } \\
\text { Azo }\end{array}$ & $\begin{array}{c}\text { Eficiência de } \\
\text { remoção de cor }(\%)\end{array}$ & $\begin{array}{c}\mathrm{k}_{1} \\
\left(\text { dia }^{-1}\right)\end{array}$ & $\begin{array}{c}\text { Desvio } \\
\text { padrão }\end{array}$ \\
\hline 0 & CR & 97,5 & 3,80 & 0,05 \\
100 & CR & 97,6 & 3,16 & 0,01 \\
250 & CR & 97,5 & 4,73 & 0,34 \\
500 & CR & 97,0 & 4,13 & 0,31 \\
1000 & CR & 96,5 & 3,61 & 0,48 \\
\hline
\end{tabular}

Tabela 2. Efeito de diferentes concentrações de sulfato na descoloração de CR com a adição do cossubstrato etanol (1,5 gDQO/L) na presença de AQDS

\begin{tabular}{cccccc}
\hline $\begin{array}{c}\text { Concentração de } \\
\text { sulfato }(\mathrm{mg} / \mathrm{L})\end{array}$ & $\begin{array}{c}\text { AQDS } \\
(\mu \mathrm{M})\end{array}$ & $\begin{array}{c}\text { Corante } \\
\text { Azo }\end{array}$ & $\begin{array}{c}\text { Eficiência de } \\
\text { remoção de cor }(\%)\end{array}$ & $\begin{array}{c}\mathrm{k}_{1} \\
\left(\mathrm{dia}^{-1}\right)\end{array}$ & $\begin{array}{c}\text { Desvio } \\
\text { padrão }\end{array}$ \\
\hline 0 & 50 & $\mathrm{CR}$ & 99,3 & 5,12 & 0,07 \\
100 & 50 & $\mathrm{CR}$ & 98,5 & 4,84 & 0,15 \\
250 & 50 & $\mathrm{CR}$ & 98,6 & 4,94 & 0,04 \\
500 & 50 & $\mathrm{CR}$ & 98,2 & 4,47 & 0,43 \\
1000 & 50 & $\mathrm{CR}$ & 98,4 & 4,20 & 0,21 \\
\hline
\end{tabular}

Em termos de eficiência máxima de remoção de cor, todos os experimentos com o corante $\mathrm{CR}$ atingiram resultados elevados, com média de 97,2 e 98,6\% na ausência e na presença de AQDS, respectivamente. Em termos de velocidade de remoção, percebe-se que as maiores constantes cinéticas foram encontradas quando se adicionaram $250 \mathrm{mg} / \mathrm{L}$ de fonte extra de sulfato.

Observando a Tabela 3, percebe-se que o corante RB5 apresentou eficiência média de remoção de cor de $87,2 \%$, na ausência de mediador redox. Os valores das constantes cinéticas aumentaram com o acréscimo da concentração da fonte extra de sulfato adicionada. Para a concentração de $1000 \mathrm{mg} / \mathrm{L}$ de sulfato, a constante cinética foi 1,7 vezes maior que a do experimento controle (sem sulfato). Os resultados das análises de sulfato indicam que houve redução de sulfato (dados não mostrados) e o sulfeto gerado funcionou como doador de elétrons para redução deste corante. Neste caso, quanto menor a relação DQO/sulfato, maior a velocidade de remoção de cor.

Tabela 3. Taxas de descoloração do corante azo RB5 na presença de diferentes concentrações de sulfato com a adição do cossubstrato etanol (1,5 gDQO/L)

\begin{tabular}{ccccc}
\hline $\begin{array}{l}\text { Concentração de } \\
\text { sulfato }(\mathrm{mg} / \mathrm{L})\end{array}$ & $\begin{array}{c}\text { Corante } \\
\text { Azo }\end{array}$ & $\begin{array}{c}\text { Eficiência de } \\
\text { remoção de cor }(\%)\end{array}$ & $\begin{array}{c}\mathrm{K}_{1} \\
\left(\mathrm{dia}^{-1}\right)\end{array}$ & $\begin{array}{c}\text { Desvio } \\
\text { padrão }\end{array}$ \\
\hline 0 & RB5 & 87,2 & 0,59 & 0,06 \\
100 & RB5 & 87,4 & 0,68 & 0,02 \\
250 & RB5 & 86,7 & 0,95 & 0,04 \\
500 & RB5 & 87,0 & 0,93 & 0,02 \\
1000 & RB5 & 87,8 & 1,00 & 0,01 \\
\hline
\end{tabular}

Nas mesmas condições, foram obtidas eficiências de remoção de cor e constantes cinéticas maiores para o corante $\mathrm{CR}$ em relação ao corante RB5, o que mostra que este último é mais recalcitrante a processos redutivos em ambiente anaeróbio. Características estruturais explicam essa diferença, pois o grande volume molecular do corante RB5 acarreta um impedimento histérico e dificulta a redução do corante, reduzindo a eficiência de remoção de cor. O corante azo $\mathrm{CR}$ mostrou elevada velocidade de quebra, provavelmente pela sua estrutura ser mais linear quando comparada ao RB5, assim diminuindo o efeito do impedimento histérico, que facilita o ataque dos micro-organismos e o torna melhor aceptor de elétrons.

Na presença de AQDS (Tabela 4), a eficiência média de remoção de cor do RB5 foi de $83,1 \%$. Os valores das constantes cinéticas obtidas foram maiores quando comparadas às obtidas sem AQDS (Tabela 3). Com a adição de $1000 \mathrm{mg} / \mathrm{L}$ de fonte extra de sulfato, o valor da constante cinética foi de $1,96 \mathrm{dia}^{-1}$, sendo 2,6 vezes maior quando comparado ao experimento em que se adicionou $100 \mathrm{mg} / \mathrm{L}$.

Tabela 4. Efeito de diferentes concentrações de sulfato na descoloração de RB5 com a adição do cossubstrato etanol (1,5 gDQO/L) na presença de AQDS

\begin{tabular}{cccccc}
\hline $\begin{array}{c}\text { Concentração de } \\
\text { sulfato }(\mathrm{mg} / \mathrm{L})\end{array}$ & $\begin{array}{c}\text { AQDS } \\
(\mu \mathrm{M})\end{array}$ & $\begin{array}{c}\text { Corante } \\
\text { Azo }\end{array}$ & $\begin{array}{c}\text { Eficiência de } \\
\text { remoção de cor }(\%)\end{array}$ & $\begin{array}{c}\mathrm{k}_{1} \\
\left(\mathrm{dia}^{-1}\right)\end{array}$ & $\begin{array}{c}\text { Desvio } \\
\text { padrão }\end{array}$ \\
\hline 0 & 50 & RB5 & 83,4 & 1,85 & 0,37 \\
100 & 50 & RB5 & 85,6 & 0,76 & 0,10 \\
250 & 50 & RB5 & 82,6 & 1,03 & 0,01 \\
500 & 50 & RB5 & 80,4 & 1,15 & 0,26 \\
1000 & 50 & RB5 & 83,1 & 1,96 & 0,40 \\
\hline
\end{tabular}

Relativo à competição entre redução do corante e outros aceptores de elétrons, observam-se na literatura efeitos contraditórios da presença de sulfato. Cervantes et al.$^{21}$ estudaram em experimentos em batelada o efeito de altas concentrações de sulfato na descoloração redutiva de diferentes corantes azo por lodo anaeróbio. Os autores encontraram pouco ou nenhum efeito do sulfato (5-10 g sulfato/L) nas taxas de descoloração do corante Reactive Orange 14 (RO14), Direct Blue 53 (DB53) e Direct Blue 71 (DB71) na ausência do mediador redox riboflavina. Entretanto, um aumento na concentração de sulfato nas garrafas que continham riboflavina $(20 \mu \mathrm{M})$ proporcionou um aumento na descoloração de todos os corantes em até 3,6 vezes, comparado com os controles que não possuíam sulfato, mas que continham riboflavina. Ou seja, percebe-se que a presença de um mediador redox facilita a transferência de elétrons oriundos da redução de sulfato para o corante azo, como visto no presente experimento. Entretanto, outras pesquisas revelaram um efeito inibitório do sulfato na redução de diferentes corantes, devido à preferência deste composto como aceptor final de elétrons., ${ }^{9,22}$

Portanto, a presença de sulfato pode tanto inibir quanto aumentar as taxas de redução do corante, sendo dependente das características do lodo anaeróbio, da concentração de sulfato e da relação DQO/sulfato. No presente estudo, como o CR foi facilmente reduzido, foram obtidas elevadas constantes cinéticas, as quais mascararam o efeito do sulfato, o que não ocorreu no processo de descoloração do RB5.

\section{Efeito da presença de sulfato e o impacto de mediadores redox na descoloração redutiva de corantes azo em reatores anaeróbios}

Para analisar o efeito do sulfato nas taxas de remoção de cor de corantes azo em reatores anaeróbios, foi feito um estudo comparativo entre os reatores controles (sem adição de fonte extra de sulfato, R1 e R2) e os reatores suplementados com fonte extra de sulfato (R3 e R4), visto que em todos havia presença de baixas concentrações de sulfato presente no meio basal. Como pode ser visto na Tabela 5, 
variou-se a concentração do cossubstrato etanol e do corante CR, para verificar o desempenho do lodo anaeróbio em diferentes condições nos reatores controles.

Tabela 5. Eficiência de remoção de cor nos reatores anaeróbios sem adição extra de sulfato R1 (livre de AQDS) e R2 (com AQDS)

\begin{tabular}{lccccc}
\hline Período & 1 & 2 & 3 & 4 & 5 \\
\hline COV do etanol $\left(\mathrm{KgDQO} / \mathrm{m}^{3} \mathrm{~d}\right)$ & 2,5 & 2,5 & 2,5 & - & 1,0 \\
Congo Red $-\mathrm{CR}(\mathrm{mM})$ & - & 0,6 & 1,2 & 1,2 & 1,2 \\
AQDS $(\mu \mathrm{M}) \mathrm{R} 1$ & - & - & - & - & - \\
AQDS $(\mu \mathrm{M}) \mathrm{R} 2$ & - & 50 & 50 & 50 & 50 \\
& - & & & & \\
Remoção de cor R1 $(\%)$ & - & 94,9 & 96,5 & 23,7 & 89,9 \\
& & $(2,7)$ & $(6,8)$ & $(10,0)$ & $(15,6)$ \\
Remoção de cor R2 $(\%)$ & - & 99,2 & 98,1 & 17,2 & 98,5 \\
& & $(2,4)$ & $(3,7)$ & $(8,3)$ & $(0,8)$ \\
\hline
\end{tabular}

No período 1, houve a aclimatação do lodo em ambos os reatores e não foi adicionado corante. No segundo período, a concentração de corante $\mathrm{CR}$ foi de $0,6 \mathrm{mM}$, sendo dobrada no período seguinte, mas mantendo-se a mesma carga orgânica volumétrica de etanol $\left(2,5 \mathrm{KgDQO} / \mathrm{m}^{3} \mathrm{~d}\right)$.

Foram obtidas elevadas remoções de cor nos períodos 2 e 3 , superiores a $90 \%$, mesmo para elevadas concentrações de corante, sendo que o reator suplementado com AQDS apresentou maior estabilidade e maiores eficiências de remoção de cor, quando comparado ao reator livre de mediador redox. No entanto, a diferença foi pequena, provavelmente devido ao fato do corante não ser tão recalcitrante aos processos redutivos. Dos Santos et al. ${ }^{6}$ em experimento com Reactive Red 2 (RR2) na concentração de $0,3 \mathrm{mM}$ e AQDS $(25 \mu \mathrm{M})$, encontraram diferenças de até $32 \%$ nas taxas de descoloração entre 2 reatores anaeróbios, sendo um deles suplementado com AQDS.

No período em que o etanol foi completamente suspenso (período 4), as eficiências de descoloração redutiva foram de apenas $23,7 \%$ (R1 - livre de AQDS) e 17,2\% (R2 - suplementado com AQDS). Quando houve novamente a adição do cossubstrato etanol (período 5), mesmo numa carga menor à carga inicial de etanol $\left(1,0 \mathrm{KgDQO} / \mathrm{m}^{3} \mathrm{~d}\right), \mathrm{o}$ lodo anaeróbio se recuperou e foram obtidas remoções de cor de $89,9 \%$ (reator R1) e $98,5 \%$ (reator R2).Vários relatos comprovam a necessidade da presença de um cossubstrato, que será oxidado no meio anaeróbio, gerando elétrons para redução de corantes. Quanto maior a disponibilidade de elétrons, maior será a eficiência de remoção de cor. Por exemplo, Brauna et al. ${ }^{23}$ obtiveram, em experimentos em batelada, taxas de descoloração do corante RR2 com $1000 \mathrm{mgDQO} / \mathrm{L}$ de etanol 2,5 vezes maiores que os valores para uma concentração de $100 \mathrm{mgDQO} / \mathrm{L}$ de etanol. Ou seja, a concentração do cossubstrato também interferiu no processo de remoção de cor.

Brás et al. ${ }^{25}$ constataram aumento na remoção de cor do corante azo Acid Orange 7 ao aumentar a concentração do cossubstrato. O'Neil et al. ${ }^{26}$ ao tratarem um efluente contendo $750 \mathrm{mg} / \mathrm{L}$ do corante azo Red $H-E 7 B$ com duas concentrações diferentes de amido, observaram um aumento na capacidade de descoloração do sistema para maiores concentrações de cossubstrato.

Nota-se que o efeito catalítico do AQDS nos reatores foi observado quando houve elétrons suficientes para redução do corante (Tabela 5). Quando houve adição de etanol, maiores eficiências de remoção de cor foram atingidas para o R2 (suplementado com AQDS). No período de ausência de doador de elétrons, o reator livre de AQDS (R1) apresentou maior eficiência de remoção de cor, provando realmente que o mediador redox precisa de um doador de elétrons externo para transferir os elétrons para o corante.
Na Tabela 6 encontram-se os resultados de remoção de cor dos reatores R3 e R4. No período 1, houve aclimatação do lodo em ambos os reatores. Nos períodos 2 e 3, houve a adição de corante CR (0,6 $\mathrm{mM}$ no período 2 e 1,2 $\mathrm{mM}$ no período 3) sendo obtidas eficiências de remoção de cor maiores que $90 \%$. Comparando os resultados com o experimento controle (R1 e R2), observa-se que a presença de fonte extra de sulfato não inibiu nem estimulou o processo de remoção de cor.

Tabela 6. Eficiências de remoção de cor do corante CR nos reatores anaeróbios $\mathrm{R} 3$ e $\mathrm{R} 4$

\begin{tabular}{llllll}
\hline Período & 1 & 2 & 3 & 4 & 5 \\
\hline $\begin{array}{l}\text { COV do etanol } \\
\text { (KgDQO/m³ d) }\end{array}$ & 2,5 & 2,5 & 2,5 & - & 1,0 \\
Congo Red-CR (mM) & - & 0,6 & 1,2 & 1,2 & 1,2 \\
AQDS ( $\mu \mathrm{M})$ R3 & - & - & - & - & - \\
& & & & & \\
AQDS ( $\mu \mathrm{M})$ R4 & - & 50 & 50 & 50 & 50 \\
& & & & & \\
Sulfato de sódio (mg/L) R3 e R4 & 250 & 250 & 250 & 250 & 250 \\
& & & & & \\
Remoção de cor (\%) R3 & - & 98,9 & 95,3 & 47,8 & 96,8 \\
& & $(0,6)$ & $(6,2)$ & $(23,7)$ & $(5,9)$ \\
Remoção de cor $(\%)$ R4 & - & 99,1 & 98,3 & 96,5 & 97,7 \\
& & $(0,4)$ & $(0,8)$ & $(3,0)$ & $(6,1)$ \\
\hline
\end{tabular}

No período 4 houve a suspensão do composto etanol nos reatores R3 e R4. Observa-se que as eficiências de remoção de cor do corante CR foram de $47,8 \%$ para o reator R3 e, interessantemente, $96,5 \%$ para o reator R4. Fazendo uma comparação com os dados dos reatores R1 e R2 nessas mesmas condições, mas como já abordado, sem adição de fonte extra de sulfato, claramente percebe-se a diferença entre as performances dos reatores, pois os reatores R1 e R2 apresentaram remoções de cor inferiores a 25\%. Assim, o reator R4 (com AQDS e fonte extra de sulfato) foi capaz de manter uma elevada capacidade de remoção de cor mesmo na ausência do cossubstrato etanol, e o reator R3 teve eficiência superior aos reatores R1 e R2.

As bactérias redutoras de sulfato tiveram um papel importante nesse processo, provavelmente reduzindo o sulfato extra adicionado pelo uso do substrato endógeno como doador de elétrons, e canalisando o sulfeto biogênico, o qual serve como doador de elétrons para o corante. Esse processo foi melhor desempenhado na presença do mediador redox (reator R4), que garantiu uma remoção de cor duas vezes superior à alcançada no reator livre de AQDS (R3).

Outra possibilidade que não se pode excluir é a capacidade do consórcio microbiano de usar o CR como fonte de carbono e energia mediado pelo AQDS, o qual só ocorreu na presença da fonte extra de sulfato. Segundo Kapdan e Alparslan, ${ }^{27}$ a razão para boas remoções de cor em condições anaeróbias na ausência de fontes extras de carbono é devida ao uso do corante como fonte de carbono e energia. Manu e Chaudhari ${ }^{3}$ ventilam a possibilidade do uso de corantes e dos produtos de sua quebra redutiva como fonte de carbono pelas arqueas metanogênicas.

Para verificar o impacto da presença de sulfato na remoção de cor anaeróbia de outro corante azo, assim como o ataque dos microorganismos ao corante na ausência de um cossubstrato, após os 5 períodos descritos para o corante $\mathrm{CR}$, os reatores R3 e R4 foram alimentados com efluente sintético contendo o corante azo RB5, cujos resultados de remoção de cor estão indicados na Tabela 7 .

Sabendo-se que o consumo de $1 \mathrm{~mol}$ de $\mathrm{O}_{2}$ representa a reação com 4 mols de elétrons, se $1 \mathrm{~mol}$ de $\mathrm{O}_{2}$ representa $32 \mathrm{~g}$ de DQO, 1 mol de elétrons corresponde a $8 \mathrm{~g}$ de DQO. Portanto, para um corante 
Tabela 7. Eficiências de remoção de cor do corante RB5 para os reatores anaeróbios R3 e R4

\begin{tabular}{lccc}
\hline Período & 1 & 2 & 3 \\
\hline $\begin{array}{l}\text { COV do etanol } \\
\left(\text { KgDQO/m }{ }^{3} \text { d) }\right.\end{array}$ & 1,0 & 1,0 & - \\
Reactive Black 5 - RB5 $(\mathrm{mM})$ & 0,3 & 0,3 & 0,3 \\
AQDS $(\mu \mathrm{M}) \mathrm{R} 3$ & - & - & - \\
AQDS $(\mu \mathrm{M}) \mathrm{R} 4$ & 50 & 100 & 100 \\
Sulfato de sódio (mg/L) R3 e R4 & 250 & 250 & 250 \\
Remoção de cor $(\%)$ R3 & $70,6(2,0)$ & $71,3(0,71)$ & $41,4(11,1)$ \\
Remoção de cor $(\%)$ R4 & $75,0(2,2)$ & $73,1(2,0)$ & $46,8(9,9)$ \\
\hline
\end{tabular}

diazo, teoricamente, são necessários 8 elétrons equivalentes para reduzir uma molécula. Como os dois corantes testados no presente estudo são diazos, eles demandam a mesma quantidade de DQO para serem reduzidos. Entretanto, o corante RB5 foi testado numa concentração molar inferior quando comparado ao CR, pois o RB5, em experimentos em batelada, mostrou-se ser mais recalcitrante a processos de redução.

Antes de iniciar o experimento com RB5, os reatores passaram por um período de transição, em que os seus afluentes continham apenas meio basal, para que fossem eliminados resíduos do corante $\mathrm{CR}$ na manta de lodo. No período 1 (Tabela 7), a concentração do corante RB5 foi de 0,3 mM ou 297,5 mg/L, mantendo-se esta concentração nas duas fases seguintes. No período 2, a concentração de AQDS foi dobrada no reator R4. No período 3, testou-se a ausência de doador de elétrons para descoloração do RB5. A concentração de sulfato extra adicionada foi mantida constante ao longo do experimento e sendo igual às das investigações com o corante CR.

Observa-se na Tabela 7 que as remoções de cor foram bem menores do que as obtidas com o corante CR, mesmo se utilizando uma concentração 3 vezes menor de corante RB5. Ou seja, o corante RB5 era realmente mais recalcitrante que o corante $\mathrm{CR}$, baseado nas diferenças estruturais entre os corantes.

O reator R4 (suplementado com AQDS) apresentou melhores resultados de remoção de cor em relação ao reator R3. Entretanto, o impacto do mediador redox AQDS foi abaixo das expectativas e dos resultados obtidos nos experimentos em batelada. Mesmo dobrando a concentração de mediador redox AQDS (período 2), a eficiência de remoção de cor no R4 permaneceu bem inferior aos valores obtidos para remoção de CR. Isto mostra que, realmente, os elétrons estão sendo impedidos de serem transferidos à molécula de corante.

Estudando o efeito do aumento da concentração de AQDS, Dos Santos et al. ${ }^{28}$ utilizaram $24 \mu \mathrm{M}$ de AQDS e obtiveram aumento da constante cinética do processo de descoloração do corante Reactive Red 2 de 1,9 vezes, comparando com a ausência de mediador redox. Utilizando-se $10 \mathrm{mM}$, o aumento foi de 5,9 vezes em relação à ausência de mediador redox.

Field e Brady ${ }^{29}$ testaram a variação de concentração do mediador redox riboflavina e observaram que para baixas concentrações deste composto $(9,1 \mu \mathrm{M})$ o aumento foi de $61 \%$ da taxa de descoloração do controle (sem mediador redox). Adicionando-se $55 \mu \mathrm{M}$ de riboflavina, a redução do corante Mordant Yellow 10 foi 2 vezes mais rápida que o controle. Ou seja, altas concentrações de riboflavina também não aumentaram significativamente a taxa de descoloração, indicando saturação cinética.

Como pode ser visto, o processo de redução do corante na presença de sulfato depende muito da estrutura do corante, como foi observado também por Albuquerque et al., ${ }^{9}$ que concluíram que a presença de sulfato foi um importante requisito para descoloração do corante azo Remazol Brilliant Violet $5 R$, ao contrário do que encontraram para o corante azo Acid Orange 7.
Observando a Tabela 7, verifica-se que no período 3 , ou seja, sem adição de etanol, as remoções de cor diminuíram drasticamente em relação ao período anterior, passando de 71,3 para $41,4 \%$ no reator R3, e de 73,1 para 46,8\% no reator R4. Comparando estes resultados com os obtidos com o corante $\mathrm{CR}$ nas mesmas condições, observa-se que o mediador redox teve menor impacto neste caso, pois a diferença entre as remoções de cor dos reatores (R3 e R4) foi bem pequena. Assim, tanto o sulfeto biogênico formado pode não ter sido canalizado para a redução do corante, mesmo na presença do AQDS, devido ao grande volume molecular deste corante, quanto pela inabilidade do consórcio microbiano de usar o RB5 como fonte de carbono e energia, mediado pelo AQDS, provavelmente também devido ao grande volume molecular do RB5.

A redução de sulfato nos reatores R3 e R4 foi comprovada pelas análises de sulfato realizadas com amostras tanto dos afluentes como dos efluentes destes reatores (dados não mostrados). Observou-se mais uma vez a utilização de elétrons oriundos da redução de sulfato para redução do corante, com a consequente remoção de cor, mesmo ocorrendo a menores taxas, quando comparado ao corante RB5. Segundo Dos Santos et al., ${ }^{30}$ a capacidade para reduzir corantes tem sido associada a uma grande variedade de micro-organismos, incluindo os fermentativos, redutores de sulfato e metanogênicos.

\section{CONCLUSÕES}

Constatou-se que a presença de sulfato tem diferentes efeitos na descoloração redutiva de corantes, que depende da concentração utilizada, da estrutura química do corante e da capacidade do inóculo de reduzir sulfato.

A presença de sulfato, nas concentrações testadas nos experimentos em fluxo contínuo, não inibiu nem estimulou o processo de remoção de cor do corante $\mathrm{CR}$, quando se tinha como cossubstrato o composto etanol, mostrando que a contribuição abiótica por adsorção e redução do corante pelo sulfeto biogênico formado era negligenciável.

Na ausência de cossubstrato, os reatores suplementados com fonte extra de sulfato tiveram desempenho melhor em relação à remoção de cor quando comparados aos reatores controles, evidenciando o papel do sulfeto biogênico para remoção de cor, em períodos de baixa concentração de DQO.

Ainda na ausência de cossubstrato com o corante $\mathrm{CR}$, o reator R4 suplementado com AQDS teve uma eficiência de remoção de cor superior a $90 \%$ e cerca de duas vezes superior à alcançada no reator livre de AQDS (R3), quer pela melhor capacidade de transferência de elétrons quer pelo uso do CR como fonte de carbono e energia, mediado pelo AQDS.

As eficiências de remoção de cor obtidas foram elevadas, em geral, mesmo para elevadas concentrações de corante, o que mostra que o sistema anaeróbio é uma alternativa viável para efluentes têxteis.

\section{AGRADECIMENTOS}

Ao Laboratório de Saneamento (Labosan) da Universidade Federal do Ceará (UFC), ao Colégico Christus, ao CNPq (Conselho Nacional de Desenvolvimento Científico e Tenológico) pelo suporte financeiro (Processo 470310/2007-3 do Edital Universal) e à assistência do Laboratório de Água (Lanágua) da UFC.

\section{REFERÊNCIAS}

1. Guaratini, C. C. I.; Zanoni, M. V. B.; Quim. Nova 2000, 23, 71.

2. Broadbent, A. D.; Basic Principles of Textile Coloration; Society of Dyers and Colourists, Canadá, 2001. 
3. Manu, B.; Chaudhari, S.; Bioresour. Technol. 2002, 82, 225.

4. Pinheiro, H. M.; Touraud, E.; Thomas, O.; Dyes Pigm. 2004, 61, 121.

5. Guo, J.; Zhou, J.; Wang, D.; Tian, C.; Wang, P.; Uddin, M. S.; Yu, H.; Water Res. 2007, 41, 426.

6. Dos Santos, A. B.; Traverse, J.; Cervantes, F. J.; Van Lier, J. B.; Biotechnol. Bioeng. 2005, 89, 42.

7. Méndez-Paz, D.; Omil, F.; Lema, J. M.; Water Res. 2005, 39, 771.

8. Singh, P.; Sanghi, R.; Pandey, A.; Iyengar, L.; Bioresour. Technol. 2007, 98, 2053.

9. Alburquerque, M. G. E.; Lopes, A. T.; Serralheiro, M. L.; Novais, J. M.; Pinheiro, H. M.; Enzyme Microb. Technol. 2005, 36, 790.

10. Van der Zee, F. P.; Villaverde, S.; Water Res. 2005, 39, 1425.

11. Souza, K. V.; Vieira, E. S.; Cestari, A. R.; Zamora, P. G. P.; Zawadzki, S. F.; $17^{\circ}$ CBEC/Mat - Congresso Brasileiro de Engenharia e Ciência dos Materiais, Foz do Iguaçu, Brasil, 2006.

12. Torrades, F.; Garcia-Montano, J.; Garcia-Hortal, J. A.; Domenech, X.; Peral, J.; Sol. Energy 2004, 95, 102.

13. Santana, M. H. P.; Da Silva, L. M.; Freitas, A. C.; Boodts, J. F. C.; Fernandes, K. C.; De Faria, L. A.; J. Hazard. Mater. 2009, 164, 10.

14. Franco, D. V.; Jardim, W. F.; Boodts, J. F. C.; Da Silva, L. M.; Clean 2008, 36, 34.

15. Cervantes, F. J.; Van der Zee, F. P.; Lettinga, G.; Field, J. A.; Water Sci. Technol. 2001, 44, 123.

16. Rau, J.; Stolz, A.; Appl. Environ. Microbiol. 2003, 69, 3448.

17. Guo, J.; Zhou, J.; Wang, D.; Tian, C.; Wang, P.; Uddin, M. S.; Yu, H.; Water Res. 2007, 41, 426.
18. Mezohegyi, G.; Bengoa, C.; Stuber, F.; Font, J.; Fabregat, A.; Fortuny, A.; Chem. Eng. J. 2008, 143, 293.

19. Cervantes, F. J.; Duong, D. T.; Roest, K.; Akkermans, A. D. L.; Lettinga, G.; Field, J. A.; Water Sci. Technol. 2003, 48, 9.

20. Dos Santos, A. B.; Cervantes, F. J.; Van Lier, J. B.; Bioresour. Technol. 2007, 98, 2369.

21. Cervantes, F. J.; Enriquez, J. E.; Galindo-Petatan, E.; Arvayo, H.; RazoFlores, E.; Field, J. A.; Chemosphere 2007, 68, 1082.

22. Cervantes, F. J.; Enriquez, J. E.; Mendoza-Hernandez, M. R.; RazoFlores, E.; Field, J. A.; Water Sci. Technol. 2006, 54, 171.

23. Brauna, C. H. C.; Mota, S.; Dos Santos, A. B.; Eng. Sanitária Amb. 2009, 14, 275.

24. APHA ; Standard Methods for the examination of water and wastewater, $21^{\mathrm{a}}$ ed., American Public Health Association: Washington, 2005.

25. Brás, R.; Ferra, M. I.; Pinheiro, H. M.; Gonçalves, I. C.; J. Biotechnol. 2001, 89, 155.

26. O`Neil, C.; Hawkes, F. R.; Hawkes, D. L.; Esteves, S.; Wilkox, S. J.; Water Res. 2000, 34, 2355.

27. Kapdan, I. K.; Alparslan, S.; Enzyme Microb. Technol. 2005, 36, 273.

28. Dos Santos, A. B.; Cervantes, F. J.; Van Lier, J.B; Appl. Microbiol. Biotechnol. 2004, 64, 62 .

29. Field, J. A.; Brady, J.; Water Sci. Technol. 2003, 48, 187.

30. Dos Santos, A. B.; Madrid, M. P.; Bok, F. A. M.; Stams, A. J. M.; Van Lier, J. B.; Cervantes, F. J.; Enzyme Microb. Technol. 2006, 39, 38. 